\title{
Letramento em Matemática no PISA: o que sabem e podem fazer os estudantes?
}

\section{Literacy in mathematics at PISA: what know and can do the students?}

\author{
Maria Isabel Ramalho Ortigão ${ }^{1}$ \\ Maria José Costa dos Santos ${ }^{2}$ \\ Rafael de Lima Lima ${ }^{3}$
}

\begin{abstract}
Resumo
Apresentamos resultados de pesquisa que buscou compreender desempenhos em Matemática de estudantes brasileiros, baseada em dados do PISA. Pesquisa foi conduzida envolvendo: análise exploratória dos microdados do PISA 2012, análise do conteúdo dos itens públicos de Matemática utilizados no PISA 2012 e aplicação desses itens a estudantes de 15 anos matriculados no $1^{\circ}$ ano do ensino médio em duas escolas públicas. Foi evidenciada porcentagem significativa de estudantes brasileiros nos níveis mais baixos da escala global e das subescalas de letramento matemático, configurando situação grave para cerca de metade de nossos estudantes. Conteúdos dos 56 itens públicos de Matemática foram analisados e classificados em relação a: especificidade do tema, contexto e exigência solicitada em sua solução. Ao aplicar esses itens ao grupo de estudantes do ensino médio, identificamos que as maiores dificuldades referem-se a cálculo da medida de área, triângulo retângulo e Teorema de Pitágoras.
\end{abstract}

Palavras-chave: PISA; Letramento matemático; Itens públicos.

\begin{abstract}
In this article, we present the results of a research that sought to understand the results in mathematics of Brazilian students, based on the PISA data. The research conducted involving different stages: exploratory analysis of PISA 2012 microdata, analysis of the content of public items of Mathematics used in the 2012 assessment and application of these items to a group of 15-year-old students enrolled in the first year of high school in two public schools. The results evidenced the existence of a significant percentage of Brazilian students located at the lower levels of the global scale and of the mathematical literacy subscales, which is a serious situation for about half of our students. The contents of the 56 public items of mathematics analyzed and classified in relation to the specificity of the theme, the context and the requirement requested in its solution. When applying these items to the group of high school students, we identified that the greatest difficulties referred to items that involved calculation of area measure, rectangle triangle and Pythagorean Theorem.
\end{abstract}

Keywords: PISA; Mathematical literacy; Public Items.

Submetido em: 10/08/2017 - Aceito em: 11/05/2018 - Publicado em: 13/06/2018

${ }^{1}$ Doutora em Educação pela Pontifícia Universidade Católica do Rio de Janeiro/PUC-Rio. Professora adjunta da Faculdade de Educação e do ProPEd da Universidade do Estado do Rio de Janeiro/UERJ, Brasil. E-mail: isabelortigao@terra.com.br.

${ }^{2}$ Doutora em Educação pela Universidade Federal do Rio Grande do Norte/UFRN. Professora adjunta na Universidade Federal do Ceará/UFC, Brasil. E-mail: mazzesantos@ufc.br.

${ }^{3}$ Mestre em Educação pela Universidade do Estado do Rio de Janeiro/UERJ/FEBF. Professor da rede municipal do Rio de Janeiro, RJ, Brasil. E-mail: rafaeldelimas@ hotmail.com. 


\section{Introdução}

Há quase trinta anos o Brasil tem convivido de forma sistemática com sistemas de avaliação da educação que, de modo geral, indicam o que se deve esperar que os estudantes aprendam em sua trajetória escolar e identificam os fatores escolares ou extraescolares que favorecem ou limitam a aquisição das competências esperadas.

Dentre esses sistemas avaliativos, destaca-se o Programa Internacional de Avaliação de Estudantes - PISA, um programa de avaliação aplicado a uma amostra de estudantes de 15 anos de idade em diversos países, dentre os quais o Brasil. A faixa dos 15 anos foi escolhida pelo Programa por corresponder ao término da escolaridade básica obrigatória na maioria dos países. A intenção é que os resultados dessa avaliação sejam utilizados pelos governos para definição ou redirecionamento de políticas educacionais, com vista a melhorias no ensino básico e numa formação mais efetiva aos jovens de cada país. O PISA é conduzido pela Organização para a Cooperação e Desenvolvimento Econômico - OCDE, entidade que reúne 34 países membros, além de outros que são convidados a participar. No Brasil, é coordenado pelo Instituto Nacional de Estudos e Pesquisas Educacionais Anísio Teixeira - INEP.

O PISA avalia as competências e habilidades ao final da escolaridade básica e examina o grau de preparação dos jovens para a vida adulta e, até certo ponto, a efetividade dos sistemas educacionais de diferentes países. Essa efetividade refere-se às realizações dos objetivos subjacentes aos sistemas educacionais, ou seja

uma visão do Ensino Médio de caráter amplo, de forma que os aspectos e conteúdos tecnológicos associados ao aprendizado científico e matemático sejam parte essencial da formação cidadã de um sentido universal e não somente de sentido profissionalizante (Brasil, 1998, p. 10).

As avaliações do PISA acontecem a cada três anos e abrangem três áreas do conhecimento: Leitura, Matemática e Ciências. Em cada edição do programa, é dada maior ênfase a uma dessas áreas, como evidencia o quadro a seguir.

Quadro 1 - Ano de aplicação do PISA de acordo com a área de conhecimento enfatizada na avaliação.

\begin{tabular}{|c|c|c|c|}
\hline \multicolumn{4}{|c|}{ Área de conhecimento priorizada na avaliação } \\
\hline \multicolumn{2}{|c|}{ Leitura } & Matemática & Ciências \\
\hline \multirow{2}{*}{$\begin{array}{c}\text { Ano de } \\
\text { aplicação }\end{array}$} & 2000 & 2003 & 2006 \\
\cline { 2 - 4 } & 2009 & 2012 & 2015 \\
\hline
\end{tabular}

Fonte: Inep.

Além dos testes, os procedimentos do PISA preveem que cada estudante responda também a um questionário sobre si próprio, sobre seus hábitos de estudo e suas percepções do contexto de aprendizagem. Os diretores das escolas selecionadas também preenchem um questionário que contém informações sobre as condições de funcionamento e de infraestrutura da escola.

O propósito deste texto é discutir os resultados de uma pesquisa que buscou compreender os resultados em Matemática de estudantes brasileiros, a partir dos dados da Zetetiké, Campinas, SP, v.26, n.2, mai./ago., 2018, p.375-389 
avaliação ocorrida em 2012, que envolveu cerca de 20 mil estudantes de 15 anos de idade, matriculados em 950 escolas públicas e privadas distribuídas nas 27 unidades federativas. A pesquisa foi conduzida envolvendo quatro etapas: (1) análise exploratória dos microdados do PISA 2012; (2) aplicação de modelos estatísticos para investigar o funcionamento dos itens entre grupos distintos; (3) análise do conteúdo dos itens públicos de Matemática utilizados na avaliação de 2012; e (4) aplicação desses itens a um grupo de estudantes de 15 anos de idade matriculados em duas escolas públicas, com o objetivo de compreender suas dificuldades ao se depararem com os itens usados na avaliação do PISA.

Neste texto, apresentamos os resultados da quarta etapa da pesquisa. Nela, um grupo de estudantes de 15 anos de idade, de duas escolas públicas, foi convidado a participar da pesquisa. A eles foram dadas as explicações sobre a proposta e seus objetivos, a fim de fornecer-lhes as informações sobre nossas intenções e procedimentos adotados. Em dois encontros em dias distintos, cada grupo de estudantes se reuniu na própria escola para discutir os itens de Matemática, suas percepções e compreensões sobre os enunciados, os conceitos envolvidos e possíveis caminhos para sua resolução.

Os encontros foram acompanhados pelo próprio professor (um dos autores do artigo), pela coordenadora da pesquisa e por dois bolsistas de iniciação científica, que auxiliaram na filmagem das discussões e no registro de todo o processo de aplicação dos itens. Os grupos foram compostos por 25 e 23 estudantes que, em 2016, cursavam o $1^{\circ}$ ano do ensino médio em suas escolas.

O texto está organizado em quatro seções, além desta introdução. Na sequência apresentamos breve descrição do PISA e a noção de letramento que embasa a avaliação em Matemática do Programa. Na continuidade, apresentamos alguns itens de Matemática do PISA 2012; em seguida, discutimos os resultados e tecemos nossas considerações finais.

\section{O PISA e a noção de Letramento em Matemática}

O conceito de letramento é recente no cenário educacional brasileiro; baseia-se nos estudos iniciados por Brian Street (1984), Kleiman (1995) e Soares (1998), associados ao debate acerca de novas formas de compreender a leitura e a escrita como processos dinâmicos em contextos significativos da atividade social, contextualizados, realizados em diferentes situações de uso e com finalidades diversas. Segundo Soares (1999), a palavra letramento

é a versão para o português da palavra da língua inglesa litteracy (...), que corresponde ao estado ou condição que assume aquele que aprende a ler e escrever. Implícita nesse conceito está a ideia de que a escrita traz consequências sociais, culturais, políticas, econômicas, cognitivas, linguísticas, quer para o grupo social em que seja introduzida, quer para o indivíduo que aprenda a usá-la. Em outras palavras: do ponto de vista individual, o aprender a ler e escrever - alfabetizar-se, deixar de ser analfabeto, tornar-se alfabetizado, adquirir a "tecnologia" do ler e escrever e envolver-se nas práticas sociais de leitura e de escrita - tem consequências sobre o indivíduo e altera seu estado ou condição em aspectos sociais, psíquicos, culturais, políticos, cognitivos, linguísticos e até mesmo econômicos; do ponto de vista social, a 
introdução da escrita em um grupo até então ágrafo tem sobre esse grupo efeitos de natureza social, cultural, política, econômica, linguística. O "estado" ou a "condição" que o indivíduo ou grupo social passam a ter, sob o impacto dessas mudanças, é que é designado por litteracy (Soares, 1999, p. 17-18).

As discussões em torno dos processos de escolarização da leitura e da escrita, em especial a partir dos estudos de Magda Soares, passam a considerar mais fortemente esse seu aspecto sociocultural. Alguns autores, ao priorizar uma das dimensões do letramento (individual ou social), explicitam definições que se diferenciam, o que tem se constituído em uma dificuldade a mais para os estudos que abordam o tema. Há especialistas que chegam a sugerir a existência de letramentos, no plural.

Seria, provavelmente, mais apropriado referirmo-nos a "letramentos" do que a um único letramento, e devemos falar de letramentos, e não de letramento, tanto no sentido de diversas linguagens e escritas, quanto no sentido de múltiplos níveis de habilidades, conhecimentos e crenças, no campo de cada língua e/ou escrita (Street, 1984, p. 47).

No âmbito da Educação Matemática brasileira, o termo letramento se torna mais evidente com a publicação, em 2004, do livro Letramento no Brasil: habilidades matemáticas $^{4}$. Nessa publicação, a concepção de Matemática como prática sociocultural ou a Matemática escolar que consegue fazer uma conexão direta entre os conteúdos escolares e formais e as diversas situações de vida dos estudantes são reportadas com a utilização de diferentes termos, tais como alfabetismo, alfabetismo funcional, letramento, literacia, numeracia, numeramento, alfabetismo matemático (Fonseca, 2004, p. 27). Apesar dessa multiplicidade, a ideia central de todos eles refere-se à capacidade de desempenhar tarefas funcionais que demandam conhecimentos e estratégias desenvolvidos em situações de uso sociocultural. Para a autora,

letramento matemático compreende as habilidades matemáticas como constituintes das estratégias de leitura que precisam ser implementadas para uma compreensão da diversidade de textos que a vida social nos apresenta com frequência e diversificação cada vez maiores (Fonseca, 2004, p. 27).

No PISA, o conceito de letramento está associado à capacidade de o aluno aplicar seus conhecimentos, analisar, raciocinar e se comunicar com eficiência, à medida que expõe, resolve e interpreta problemas em diversas situações. Especificamente, em relação à Matemática, refere-se à

capacidade de um indivíduo identificar e compreender o papel que a Matemática desempenha no mundo real, de fazer julgamentos bem fundamentados e de usar e se envolver na resolução matemática das necessidades de sua vida, enquanto cidadão consciente, construtivo e reflexivo (OCDE, 2013, p. 21).

A noção de letramento adotada pelo Programa relaciona-se com o uso mais abrangente e funcional da Matemática, o que exige do estudante a capacidade de reconhecer e

\footnotetext{
${ }^{4}$ Fonseca, M. C. F. R. (Org.). Letramento no Brasil: habilidades matemáticas. São Paulo: Global, 2004. 
formular problemas matemáticos em variadas situações de sua vida. Para o PISA, o desenvolvimento do letramento é um processo de aprendizagem ao longo da vida e, portanto, mais amplo do que a noção histórica da capacidade de ler e escrever (OCDE, 2013).

Diferentemente de outras avaliações internacionais (IEA, TIMMS, OREALC, por exemplo), o PISA não se concentra somente nos conteúdos curriculares; enfatiza as competências necessárias à vida moderna. Busca, portanto, verificar a operacionalização de esquemas cognitivos nas diferentes áreas de conhecimento. Em Matemática, o letramento é avaliado em termos de três dimensões:

- O conteúdo de Matemática, definido primeiramente em termos de conceitos matemáticos mais amplos (como estimativa, mudança e crescimento, espaço e forma, raciocínio lógico, incerteza e dependências e relações) e secundariamente em relação a ramos do currículo (relações numéricas, álgebra, geometria e tratamento da informação);

- O processo da Matemática, definido pelas competências matemáticas gerais, que incluem o uso da linguagem matemática, escolha de modelos e procedimentos e habilidades de resolução de problemas. No entanto, a ideia não é separar essas habilidades em diferentes itens de teste, já que se pressupõe que uma série de competências será necessária para desempenhar qualquer tarefa matemática. Essas competências são organizadas em três classes: a primeira consiste na realização de operações simples; a segunda exige o estabelecimento de conexões para resolver problemas; a terceira consiste de raciocínio matemático, generalização e descobertas, e exige que os alunos façam análises, identifiquem elementos matemáticos de uma dada situação e proponham problemas;

- Os contextos, compreendidos como as situações nas quais a Matemática é usada, variando de contextos particulares àqueles relacionados com questões científicas e públicas mais amplas (OCDE, 2013).

Para cada dimensão avaliada, existe uma escala contínua em que os níveis de desempenho dos alunos e o posicionamento deles ao longo da escala estão representados pelo número de pontos alcançados. Em Matemática, as competências são avaliadas em itens que abrangem desde a realização de operações básicas até as habilidades de alta ordem, envolvendo raciocínio e descobertas matemáticas.

Essas competências especificamente são sintetizadas em três grupos: reprodução, conexão e reflexão (OCDE, 2013). O primeiro compreende os processos cognitivos requeridos para que o estudante demonstre as habilidades matemáticas que estão ligadas de maneira muito próxima ao que é usualmente entendido como conteúdo. Na maioria das vezes, a solução do item da prova está apoiada em dados e fatos memorizados e na execução de ações repetidas. O segundo parte do anterior, mas envolve os processos cognitivos exigidos para que o estudante possa demonstrar habilidades relacionadas ao saber fazer, mesmo que de maneira incipiente. A resolução das tarefas demanda a reunião de ideias para solucionar problemas matemáticos diretos, com maior interpretação da situação. O terceiro desenvolve-se a partir do grupo de conexão, mas abrange habilidades necessárias para a 
resolução de tarefas que precisam de um pensamento matemático mais amplo, exigindo insight, reflexão e até mesmo criatividade para a resolução do problema.

Os conteúdos matemáticos propostos nos itens do PISA são organizados em quatro áreas estruturantes: Quantidade, Espaço e forma, Mudanças e relações, Incerteza. Para os organizadores da avaliação, as três primeiras constituem a essência de qualquer currículo de Matemática da educação básica. A quarta (Incerteza) atende ao caráter mais abrangente da competência matemática e se conecta com as necessidades da vida diária do cidadão. A título de exemplo, apresentamos a seguir um exemplo de item utilizado na avaliação do PISA 2012. Destacamos que a apresentação da imagem é feita tal como aparece nos cadernos de teste, exceto o tamanho original, que foi reduzido.

ESCALANDO O MONTE FUJI

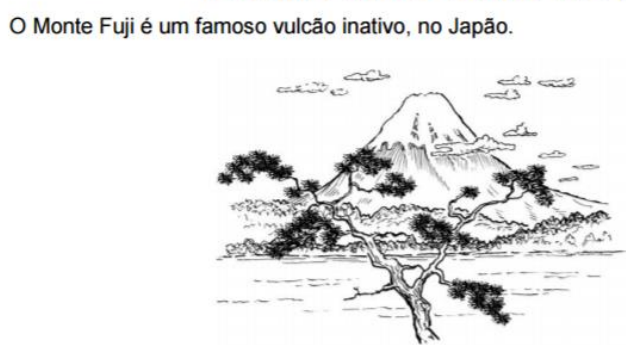

Questão 1: ESCALANDO O MONTE FUJI

O Monte Fuji está aberto ao público para escaladas somente entre $1^{\circ}$ de julho e 27 de agosto, todos os anos. Cerca de 200000 pessoas escalam o Monte Fuji nesse periodo.

Em média, aproximadamente quantas pessoas escalam o Monte Fuji por dia?

A 340

C 3400

D 7100

Figura 1 - Exemplo de item de Matemática (público) - PISA 2012.

Fonte: INEP.

O exemplo apresentado refere-se a um item situado na subárea Quantidade, que avalia a habilidade de o estudante identificar uma taxa média diária, dados um número total e um período específico de tempo (datas fornecidas). Segundo o Relatório PISA (OCDE, 2013), o item apoia-se em um contexto social de vida jovem que envolve o conhecimento e a aplicação de noções de média aritmética.

Os resultados dos desempenhos dos estudantes no PISA são fornecidos em uma escala na qual a média dos países da OCDE é padronizada em 500, com 100 de desvio padrão. Isso significa que aproximadamente dois terços dos estudantes participantes obtiveram pontuação entre 400 e 600 pontos. Para calcular essa média, considerou-se como se todos os países tivessem mil estudantes participantes, a fim de evitar que a média da OCDE se inclinasse para os países com maior número de estudantes. No cálculo dessa média, o PISA adota a Teoria da Resposta ao Item (TRI) como abordagem metodológica. A tabela a seguir apresenta o número de estudantes brasileiros avaliados e as médias globais obtidas em cada edição do 
PISA, de 2000 a 2015.

Tabela 1 - Número de participantes e desempenho médio de estudantes brasileiros por área de conhecimento PISA Brasil 2003 a 2015

\begin{tabular}{cccccccc}
\hline & PISA 2000 & PISA 2003 & PISA 2006 & PISA 2009 & PISA 2012 & PISA 2015 \\
\cline { 1 - 4 } $\begin{array}{c}\text { Número de alunos } \\
\text { participantes }\end{array}$ & 4.893 & 4.452 & 9.295 & 20.127 & 18.589 & 23.141 \\
\hline \multicolumn{7}{c}{ Desempenho médio } \\
\hline Leitura & 396 & 403 & 393 & 412 & 410 & 407 \\
Matemática & $\mathbf{3 3 4}$ & $\mathbf{3 5 6}$ & $\mathbf{3 7 0}$ & $\mathbf{3 8 6}$ & $\mathbf{3 9 1}$ & $\mathbf{3 7 7}$ \\
Ciências & 375 & 390 & 390 & 405 & 405 & 401 \\
\hline
\end{tabular}

Fonte: OCDE 2015 e Microdados do PISA. Elaboração própria.

Essa tabela evidencia um aumento significativo na quantidade de estudantes brasileiros de 15 anos testados pelo Programa em escolas públicas e privadas de todas as regiões geográficas do País. Evidencia ainda que o desempenho médio do Brasil tem melhorado ao longo do tempo. Em Matemática, por exemplo, passamos de uma média de 356, em 2003, para 391, em 2012, e 377 em 2015. Se considerarmos as duas avaliações em que a ênfase recorreu sobre Matemática (2003 e 2012), observa-se um aumento de 35 pontos nas médias globais. Cerca de metade desse aumento, segundo relatório da OCDE (2015), pode ser explicada por mudanças na composição demográfica e socioeconômica da população estudantil.

A despeito da melhoria nos resultados globais dos estudantes brasileiros, o relatório da OCDE (2015) evidencia que 60\% dos estudantes no Brasil têm fraco aproveitamento em Matemática, o que significa que, na melhor das hipóteses, eles podem apresentar explicações matemáticas óbvias e explicitamente evidenciadas. Poucos estudantes no Brasil posicionamse nas faixas mais elevadas da escala. A tabela a seguir apresenta as médias em Matemática das subescalas do PISA 2012 e a distribuição dos estudantes brasileiros nos seis níveis da escala de Matemática do PISA.

Tabela 2 - Médias nas Subescalas e distribuição percentual de estudantes nos níveis em Matemática PISA 2012.

\begin{tabular}{lcccccccc}
\hline \multicolumn{1}{c}{ Subescalas } & $\begin{array}{c}\text { Média } \\
(\mathrm{Dp})\end{array}$ & $\begin{array}{c}\text { Abaixo } \\
\text { Nível 1 }\end{array}$ & Nível 1 & Nível 2 & Nível 3 & Nível 4 & Nível 5 & Nível 6 \\
\hline $\begin{array}{l}\text { Indeterminação } \\
\text { e dados }\end{array}$ & $\begin{array}{c}402,1 \\
(2,0)\end{array}$ & 26,5 & 35,1 & 25,5 & 10,0 & 2,5 & 0,3 & 0,0 \\
Quantidade & $\begin{array}{c}392,9 \\
(2,5)\end{array}$ & 36,5 & 27,0 & 20,2 & 10,5 & 4,3 & 1,3 & 0,2 \\
Espaço e forma & $\begin{array}{c}380,0 \\
(2,0)\end{array}$ & 40,3 & 30,6 & 18,8 & 7,3 & 2,4 & 0,6 & 0,1 \\
$\begin{array}{l}\text { Mudanças e } \\
\text { relações }\end{array}$ & $\begin{array}{c}371,5 \\
(2,7)\end{array}$ & 46,3 & 24,0 & 16,5 & 8,4 & 3,3 & 1,1 & 0,3 \\
\hline
\end{tabular}

Fonte: Microdados PISA 2012 - Brasil. Elaboração própria.

Notadamente, a Tabela 2 aponta a situação grave em que a maioria dos estudantes brasileiros se concentra. Observamos que em todas as subescalas há forte concentração de estudantes nos níveis mais baixos e apenas poucos estudantes (pouco mais de 10\%) 
distribuem-se nos níveis superiores das subescalas.

A busca por compreender tais resultados conduziu-nos à análise do conteúdo dos itens usados pelo Programa ${ }^{5}$ e à aplicação desses itens a um grupo de estudantes com características semelhantes às da amostra brasileira do PISA, como informado anteriormente. Na seção que segue discutimos esses resultados.

\section{Análises dos itens públicos do PISA 2012}

Em 2012, o PISA disponibilizou ao público em geral um total de 56 itens de Matemática (OCDE, 2013). A tabela a seguir apresenta a distribuição desses itens de acordo com a subárea avaliada.

Tabela 3 - Quantidade de itens públicos por subárea - PISA 2012 Matemática

\begin{tabular}{lc}
\hline Subárea da Matemática & Número de itens públicos \\
\hline Indeterminação e dados & 12 \\
Quantidade & 15 \\
Espaço e forma & 14 \\
Mudanças e relações & 15 \\
\hline Total de itens públicos & 56 \\
\hline
\end{tabular}

Fonte: OCDE 2013. Elaboração própria.

Em nosso estudo, todos os 56 itens foram analisados e classificados de acordo com seus conteúdos. Como já afirmado, além da análise de conteúdo, por meio do uso de ferramentas estatísticas, foi determinado para cada item o percentual de acerto pelos estudantes brasileiros. Também submetemos os itens a estudantes do $1^{\circ}$ ano do Ensino Médio com o intuito de conhecer que dificuldades surgem quando eles se deparam com itens como os do PISA. Cabe ressaltar que não tivemos intenção de determinar o percentual de acertos dos itens, mas apenas de buscar hipóteses que nos ajudassem a compreender os baixos índices de acerto nos itens de Matemática do PISA por estudantes brasileiros.

Dada a limitação de páginas deste texto, na continuidade apresentamos a análise de dois desses itens. Aqui, escolhemos trazer dois itens da subárea Espaço e Forma, que abrange questões sobre figuras geométricas e sobre grandezas e medidas. Dos 14 itens públicos aplicados pelo PISA 2012, cinco abordam questões envolvendo ideias de área de figuras planas, quatro envolvem noções de círculo e circunferência, três referem-se a aplicações do Teorema de Pitágoras e dois abordam aspectos de figuras espaciais. A tabela a seguir apresenta uma classificação dos conteúdos dos itens públicos da subárea Espaço e Forma.

Tabela 4 - Distribuição dos itens públicos do PISA 2012 - subárea Espaço e forma, segundo seus conteúdos

\begin{tabular}{lc}
\hline Conteúdo dos itens & Quantidade de Itens \\
Espaço e forma & 5 \\
\hline Área de figura plana & 4 \\
\hline Círculo / Circunferência & \\
\hline
\end{tabular}

\footnotetext{
${ }^{5}$ Apenas os itens públicos e disponíveis no site do INEP (OCDE, 2013) são considerados nesta pesquisa. 
DOI: https://doi.org/10.20396/zet.v26i2.8650093

Aplicação do Teorema de Pitágoras 3

Visualização espacial 2

Total de itens da subárea Espaço e forma 14

Fonte: OCDE 2013. Elaboração própria.

Na continuidade, discutimos os dois exemplos de itens escolhidos.

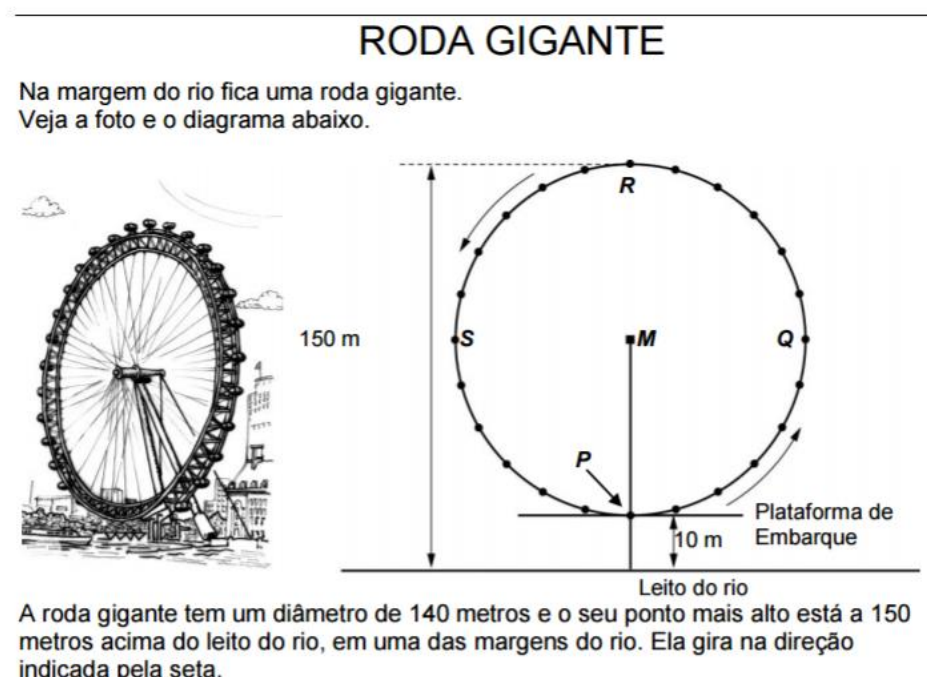

indicada pela seta.

Questão 1: RODA GIGANTE
A letra $M$, no diagrama, indica o centro da roda gigante. Quantos metros (m) sobre o
leito do rio está o ponto M?
Resposta:

\section{Questäo 2: RODA GIGANTE}

A roda gigante gira em velocidade constante. A roda faz uma rotação completa em exatamente 40 minutos.

João inicia o passeio na roda gigante na plataforma de embarque $P$.

Onde João estará depois de meia hora?

A $\operatorname{Em} R$

B Entre ReS

C Em S

D Entre $S$ e $P$

Figura 2 - Item público de Matemática - PISA 2012 Fonte: OCDE/INEP. PISA.

Segundo o relatório do PISA (OCDE, 2013), trata-se de um item da subárea Espaço e forma, que exige que o estudante conheça os significados de diâmetro e raio da circunferência, aplicados a um contexto social, em que o respondente precisa empregar conceitos aprendidos na escola para responder adequadamente. Os resultados estatísticos evidenciam um percentual de acerto bastante baixo (10,9\% e $8,1 \%$, respectivamente nas questões 1 e 2). Ainda de acordo com o relatório, tais questões situam-se, respectivamente, nos níveis 3 e 4 da escala de proficiência, evidenciando que a primeira questão é ligeiramente mais fácil que a segunda. 
Para acertar o item, o estudante deve ser capaz de interpretar e utilizar representações baseadas em diferentes fontes de informação e de raciocinar diretamente a partir delas. $\mathrm{Na}$ questão 1, é necessário perceber, a partir da análise do esquema figurativo, que o diâmetro da circunferência da roda-gigante mede 140 metros e, portanto, o raio é igual a 70 metros. Somando a medida do raio à distância da plataforma de embarque ao leito do rio (10 metros), obtém-se a medida de 80 metros.

Com relação à questão 2, o estudante deve ser capaz de perceber a relação de proporcionalidade entre o tempo e a rotação. Para atingir o crédito completo na questão 2, o aluno precisa perceber que em 40 minutos a roda gigante dá uma volta completa (360 graus), em 20 minutos completa meia volta e em 10 minutos um quarto de volta. Portanto, em 30 minutos João estará na posição "S" da curva.

Ao submetermos esse item aos estudantes do $1^{\circ}$ ano do Ensino Médio nos dois grupos, de modo geral não percebemos, por parte dos alunos, dificuldades na compreensão do contexto da questão. Em ambos os grupos, os estudantes comentaram que sabiam o que significava uma roda-gigante e alguns afirmaram terem andado na grande roda-gigante de Copacabana, à época do evento Rio+ $20^{6}$. A seguir está um exemplo de resolução apresentada por um dos estudantes.

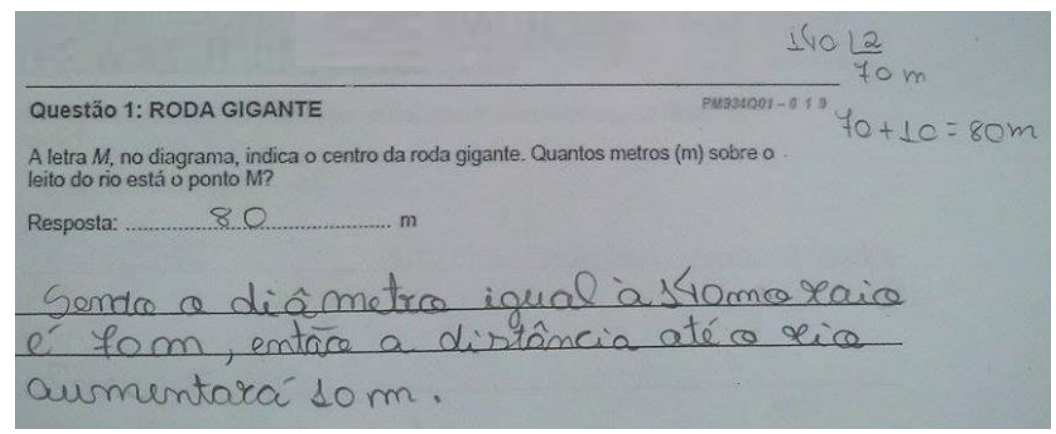

Figura 3 - Solução apresentada por um estudante do EM à questão 1 do item Roda-Gigante Fonte: Própria.

Com relação à questão 2 desse item, alguns estudantes apresentaram um pouco de dificuldade, em especial porque demoraram a identificar a relação de proporcionalidade entre as duas grandezas envolvidas. Ao discutir entre eles as possíveis soluções, perceberam que podiam determinar a posição de João no tempo de 10 minutos e, com isso, solucionaram o problema. A Figura 4 ilustra a solução encontrada de um dos estudantes.

\footnotetext{
${ }^{6}$ Evento ocorrido na cidade do Rio de Janeiro em junho de 2012 para marcar os vinte anos de realização da Conferência das Nações Unidas sobre Meio Ambiente e Desenvolvimento Sustentável (Rio-92) e definir a agenda do desenvolvimento sustentável para as décadas seguintes.
} 


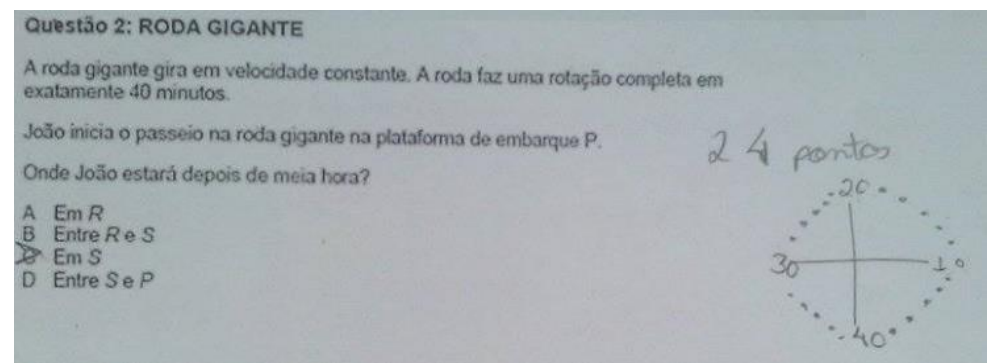

Figura 4 - Solução apresentada por um estudante do EM à questão dois do item Roda-Gigante. Fonte: Própria.

O segundo item que trouxemos para ilustrar o artigo, também da subárea Espaço e forma, requer que o estudante "use sua habilidade espacial para identificar a imagem em 3D correspondente a outra imagem dada em 3D” (INEP, 2013, p. 27).

\section{GARAGEM}

A série "básica" de um fabricante de garagens inclui modelos com apenas uma janela e uma porta.

Jorge escolhe o seguinte modelo da série "básica". A posição da janela e da porta são as mostradas aqui.

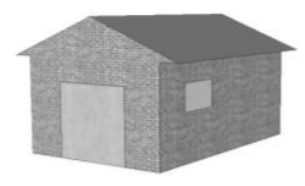

les Stão 1: GARAGEM

As ilustraçōes abaixo mostram modelos "básicos" diferentes, vistos de trás. Apenas uma destas ilustraçōes corresponde ao modelo acima, escolhido por Jorge.

Qual modelo Jorge escolheu? Circule A, B, C ou D.

A

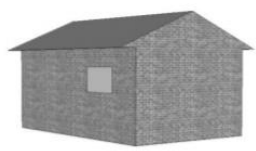

C

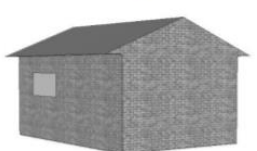

B

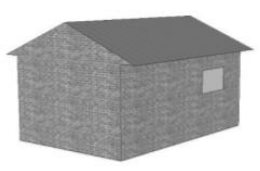

D 
DOI: https://doi.org/10.20396/zet.v26i2.8650093

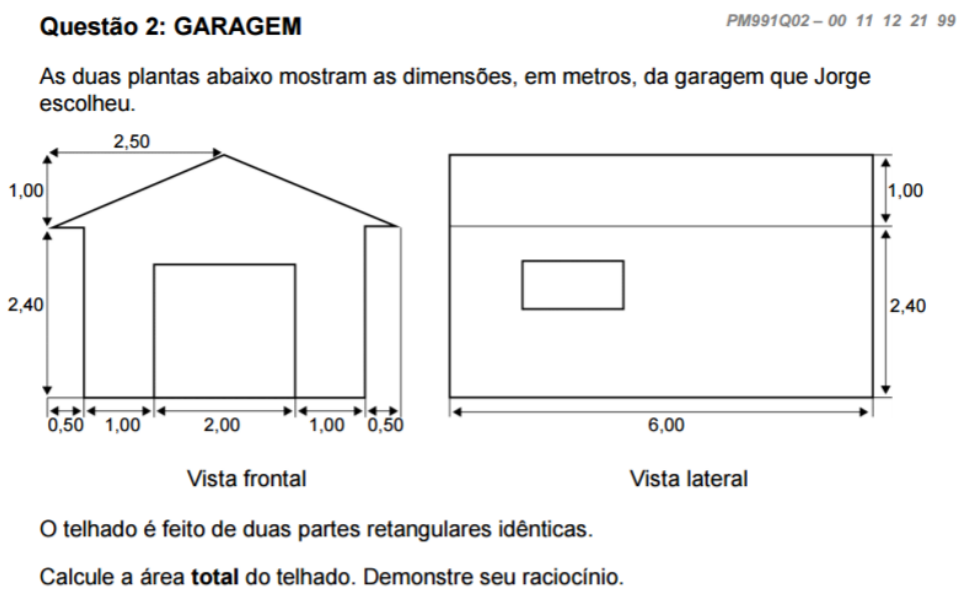

Figura 5 - Item público de Matemática - PISA 2012

Fonte: OCDE/INEP. PISA.

Segundo o relatório do PISA (INEP, 2013), trata-se de um item que exige que o estudante interprete uma situação do contexto ocupacional. Os resultados estatísticos mostram uma diferença significativa nos percentuais de acerto quando comparamos as questões 1 e 2 desse item (53,3\% e 7,6\%, respectivamente). Tal diferença evidencia que a primeira questão é significativamente mais simples aos estudantes brasileiros do que a segunda, que envolve interpretar um esquema e calcular a área de um retângulo utilizando o Teorema de Pitágoras ou medições. A primeira questão requer a utilização de competências espaciais para identificar uma vista 3D correspondente a outra vista 3D dada.

Ao submetermos este item aos estudantes nas duas escolas públicas, os resultados foram compatíveis com o observado nas estatísticas gerais. Ou seja, a primeira questão mostrou-se bastante simples, mas a segunda mostrou-se difícil aos estudantes. A Figura 6, a seguir, exemplifica a solução de um estudante que participou da pesquisa.

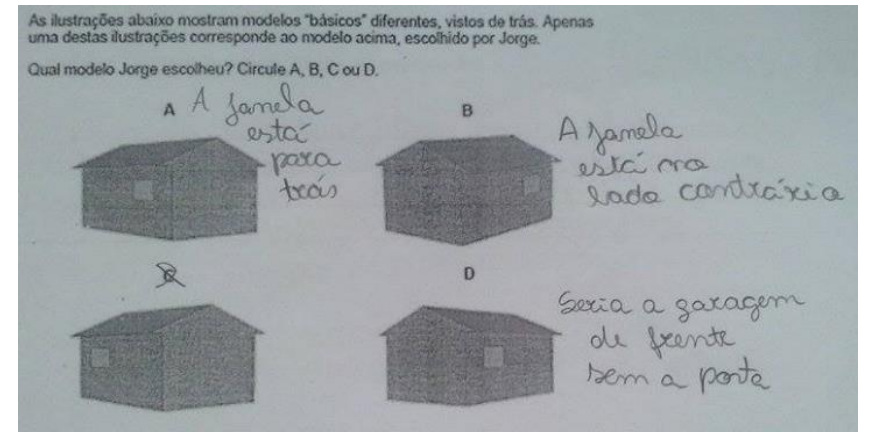

Figura 6 - Solução apresentada por um estudante do EM à questão 1 do item Garagem. Fonte: Própria.

Segundo o estudo de Carvalho e Ferreira (s/d), propostas envolvendo visualização e pensamento geométrico nas aulas de Matemática são recentes no Brasil. Por meio de um levantamento das teses e dissertações disponíveis nas bibliotecas virtuais dos programas de pós-graduação stricto sensu de Ensino de Ciências e Matemática ou Educação Matemática 
reconhecidos pela Capes, os autores verificaram que a temática ainda é pouco explorada nos cursos de licenciatura em Matemática e no âmbito da formação continuada de professores. Para os autores,

É importante promover o aprimoramento de práticas pedagógicas, o que inclui, dentre outros aspectos, a utilização de recursos didáticos que auxiliem significativamente na melhoria do processo de ensino e aprendizagem de visualização e pensamento geométrico em todos os níveis de ensino, dando especial atenção ao contexto nos quais os estudos são promovidos, permeando características da realidade local em termos de disponibilidade de materiais e recursos humanos (Carvalho; Ferreira (s/d)).

$\mathrm{Na}$ resolução da segunda questão desse item a maioria dos estudantes de nossa amostra sequer percebeu que envolvia a aplicação do Teorema de Pitágoras. De modo geral, a maioria considerou, erroneamente, a área do telhado como sendo de 12 metros quadrados $(2 \times 1 \times 6=12)$. Alguns estudantes, além de determinar a área do quadrado $(6 \times 1)$, também determinaram a área do triângulo de lados $2,5 \mathrm{~m}$ e $1 \mathrm{~m}$, adicionando o resultado ao cálculo da área do retângulo, como mostra o esquema de solução a seguir.

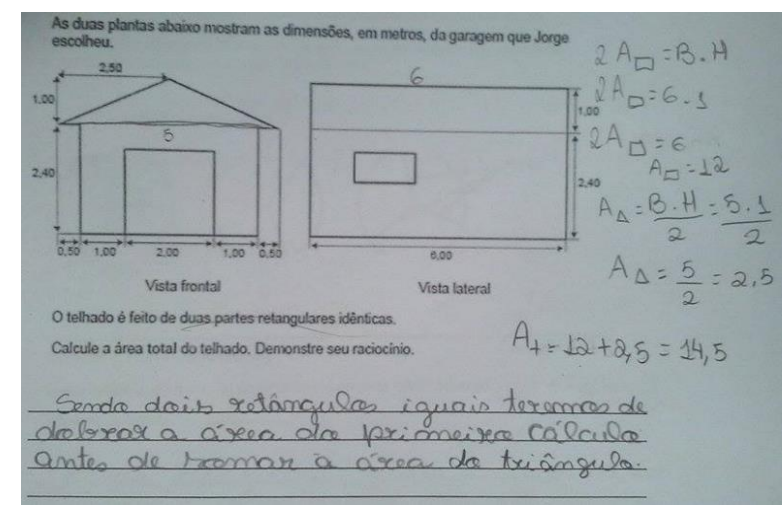

Figura 7 - Solução errada apresentada por um estudante do EM à questão 2 do item Garagem.

Fonte: Própria.

Somente depois de muita discussão, com a ajuda do professor da turma, alguns poucos alunos perceberam que a lateral do telhado correspondia à hipotenusa do triângulo retângulo desenhado na figura. Esses alunos perceberam que deveriam usar o Teorema de Pitágoras para calcular a medida, mas mesmo assim tiveram dificuldade para resolver a questão. Para eles, havia "excesso de informação, como se fosse uma pegadinha" (depoimento de um aluno).

O Teorema de Pitágoras tem sido foco de diversas investigações como, por exemplo, as desenvolvidas por Grangeiro, Pegado e Costa (2012), Tashima e Silva (2008), Mottin (2004) e Bastian (2000). Os quatro estudos, embora conduzidos com abordagens diferentes, objetivaram investigar dificuldades de estudantes brasileiros na compreensão de ideias associadas ao referido teorema.

Os resultados de nosso estudo, à luz dos trabalhos citados, apontam dificuldades dos 
estudantes em lidar com aplicação do Teorema de Pitágoras, em especial em decorrência de:

- não identificação do triângulo retângulo e de seus elementos: não percepção do ângulo reto de um triângulo quando este não se encontra na "base" horizontal (como o que ocorreu no desenho da planta da garagem); não identificação da hipotenusa e dos catetos.

- pouca familiarização na aplicação de regras e estratégias de cálculo envolvendo o Teorema de Pitágoras: de modo geral, ao perceberem a possibilidade de aplicação do teorema, os estudantes sabiam recitar que "o quadrado da hipotenusa é a soma do quadrado dos catetos", mas não souberam aplicar essa regra para determinar a medida da hipotenusa. Para Tashima e Silva (2008), esse tipo de dificuldade está relacionado com a pouca familiaridade em estabelecer a condição necessária para a igualdade pitagórica.

- dificuldades no desenvolvimento das operações matemáticas: uma das principais dificuldades encontradas pelos estudantes foi o desenvolvimento das operações matemáticas de potenciação e radiciação, em virtude da falta de conhecimento dos alunos ou provavelmente por falta de atenção.

\section{Considerações finais}

Buscamos discutir neste artigo, ainda que resumidamente, os resultados de uma investigação que analisou os itens públicos de Matemática usados no PISA 2012. O estudo fez uso de ferramentas estatísticas para analisar as médias em Matemática (globalmente e nas subescalas), a distribuição percentual dos estudantes ao longo das escalas e o percentual de acertos nos itens de Matemática dessa edição do Programa. Também analisou o conteúdo dos itens na tentativa de identificar possíveis causas dos baixos índices de acerto. Para auxiliar nesta etapa da pesquisa, os itens foram submetidos a uma amostra de estudantes de 15 anos de idade que em 2015 cursavam o $1^{\circ}$ ano do Ensino Médio em duas escolas públicas situadas no Estado do Rio de Janeiro.

Verificamos, com o estudo, que existe uma porcentagem significativa de estudantes brasileiros avaliados pelo PISA como situados nos níveis mais baixos da escala de letramento matemático, o que configura uma situação grave para cerca de metade dos nossos jovens. A comparação de resultados obtidos em Matemática no PISA 2003 e 2012 indica que, neste domínio, houve ligeira melhora. Contudo, os resultados do PISA evidenciam que os alunos, mesmo depois de frequentarem a escola por muitos anos, não estão alcançando as competências em Matemática esperadas pela OCDE.

De modo geral, há evidências de que os alunos brasileiros não desenvolvem as suas capacidades de lidar com a Matemática em situações que exigem raciocínio, criatividade e argumentação.

\section{Agradecimentos}

A pesquisa referenciada neste texto foi apoiada por Faperj/JCNE e Capes/PNPD-ProPEd. 
DOI: https://doi.org/10.20396/zet.v26i2.8650093

\section{Referências}

Bastian, I. V. (2000). O Teorema de Pitágoras. Dissertação de Mestrado em Educação Matemática. São Paulo: Pontifícia Universidade Católica de São Paulo.

Instituto Nacional de Estudos e Pesquisas Educacionais Anísio Teixeira (INEP). (2013). Relatório Nacional PISA 2012: resultados brasileiros. São Paulo: Fundação Santillana/Organização para a Cooperação e Desenvolvimento Econômico (OCDE).

Fonseca, M. C. F. R. (Org.). (2004). Letramento no Brasil: habilidades matemáticas. São Paulo: Global.

Grangeiro, M. G., Couto, A. P. N., \& Costa, A. C. (2012). Análise de erros em questões de teorema de Pitágoras: um estudo com alunos do Ensino Fundamental. Trabalho apresentado no XII Encontro Nacional de Educação Matemática. (ISSN 2178-034X). Disponível em: http://www.sbem.com.br/enem2016/anais/pdf/5481_4329_ID.pdf. Acesso em 12 de novembro, 2013.

Kleiman, A. (Org.). (1995). Os significados do letramento. Campinas: Mercados de Letras.

Mottin, E. A. (2004). Utilização de material didático-pedagógico em ateliês de matemática para o estudo de Teorema de Pitágoras. 2004. Dissertação de Mestrado em Ciências e Matemática. Porto Alegre: Pontifícia Universidade Católica do Rio Grande do Sul.

Organization for Economic Co-Operation and Development (OECD). (2013). Education at a Glance 2013 OECD indicators. OECD Publishing.

Organization for Economic Co-Operation and Development (OECD). (2016). PISA 2015 Assessment and Analytical Framework. Paris: OECD Publishing.

Soares, M B. (2004). Letramento e alfabetização: as muitas facetas. Revista Brasileira de Educação, Rio de Janeiro, (25), 5-17.

Soares, M. B. (1998). Letramento, um tema em três gêneros. Belo Horizonte: Autêntica.

Soares, M. (1999). Letramento: um tema em três gêneros. São Paulo: Autêntica.

Street, B. (1984). Literacy in theory and practice. Cambridge: Cambridge University Press.

Tashima, M. M., \& Silva, A. L. (2015). As lacunas no ensino-aprendizagem da Geometria. Retirado em 18 de novembro, 2015, de: http://www.gestaoescolar.diaadia.pr.gov.br/arquivos/File/producoes_pde/artigo_mari na_mass aco_tashima.pdf. 